\title{
Throughputs of oral hygiene programmes offered at Sefako Makgatho Health Sciences: a retrospective comparison
}

SADJ November 2021, Vol. 76 No. 10 p596 - p601

SR Mthethwa', TS Gugushe ${ }^{2}$, P M Nyalunga ${ }^{3}$

\begin{abstract}
Introduction

The expansion of the scope of practice of the profession of oral hygiene necessitated the discontinuation of a two-year diploma programme.
\end{abstract}

Aims and objectives

To describe and compare the progress to qualification of three cohorts of oral hygiene students enrolled in the diploma and degree programmes at Sefako Makgatho Health Science University. Trends in throughputs were investigated.

\section{Design}

A comparative cross-sectional study.

\section{Methods}

Academic records of three cohorts of first year oral hygiene students enrolled in the diploma and degree programmes were followed up. Data related to the demographic characteristics, numbers enrolled, numbers who dropped out, and the numbers who graduated were acquired and then captured in Microsoft Excel software.

\section{Results}

There was gender parity in enrolment for the diploma programme. Female students constituted the majority of enrolees for the degree programme. The average first year pass rate $(83.8 \%$ vs $75.8 \%)$ as well as average throughput

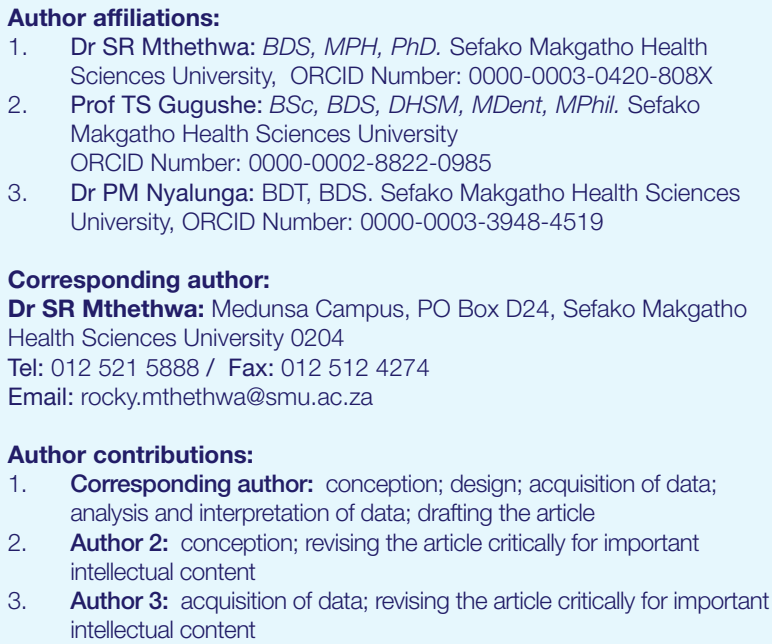

3. Author 3: acquisition of data; revising the article critically for important intellectual content

(62.5\% vs $56.1 \%$ ) of the degree programme was higher than that for the diploma programme. Linear trends between cohort size and throughput were not observed. The difference in combined output between the programmes was not statistically significant.

\section{Conclusion}

The average throughput of the degree programme was higher than that for the diploma programme

\section{INTRODUCTION AND BACKGROUND}

The time it takes to qualify as an oral hygienist at the Oral Health Centre of Sefako Makgatho Health Sciences University, a dental school and referral hospital in Garankuwa on the outskirts of Pretoria changed significantly in 2014 when a two-year diploma, which had been offered since the mid-1970s, was discontinued in favour of a threeyear degree. This change was in line with the government gazetted expansion of the scope of practice. ${ }^{1}$ The degree programme in oral hygiene is currently offered at the Dental Schools of the University of the Western Cape (UWC), University of KwaZulu-Natal (UKZN), University of the Witwatersrand (Wits), Sefako Makgatho Health Sciences University (SMU) and University of Pretoria (UP). A total of 342 students were enrolled at the five dental schools in the year 2020. This figure does not give an indication of the students' progress to degree.

The throughput, also referred to as the completion rate or graduation rate $^{3}$, of oral hygiene programmes at the five dental schools has not previously been described. The results of such a study could be useful to policy-makers in developing human resources plan for oral health and to dental schools' management in identifying impediments to graduation in order to offer the necessary academic and mentoring support to enable success should there be a need. The throughputs of the dentistry and dental therapy courses at SMU have recently been established. They were found to be $40 \%$ and $45 \%$ respectively. 4,5 These findings are not very encouraging. They indicate that less than half of all students registered in either programme graduated within the regulation time. This is unfortunate as oral health personnel, including dental assistants, oral hygienists, dental therapists, and dentists, have been estimated to constitute 0.2 per 1000 population. ${ }^{6}$

Oral hygienists are indispensable members of oral health care teams. The Health Professions Council of South Africa 
(HPCSA) defines oral hygienists as "health professionals devoted to the prevention of diseases and the promotion and improvement of the public's health". ${ }^{7}$ Oral hygienists work in a range of dental settings, from general private practice, specialised private practice, state health, or lecturing in the various training institutes across the country. ${ }^{8}$ They can also work in residential aged care facilities. ${ }^{9,10} \mathrm{~A}$ significant majority of oral hygienists are employed in private practice. ${ }^{11}$ Surprisingly, the number of oral hygienists employed in the public sector increased steadily from 127 to 194 between 2002 and 2010. ${ }^{12}$ One thousand two hundred and fifty-seven oral hygienists are currently registered with the HPCSA. ${ }^{2}$ The analysis of public sector data has established the oral hygienist to population ratio to be a meagre 0.04 per $10,000 .^{12}$

In light of the statistics, a study of the contribution of SMU oral hygiene programmes towards the oral health personnel needs of the country is warranted.

\section{OBJECTIVES OF THE STUDY}

To describe the demographic characteristics and track and compare the progress to qualification of three cohorts of first year oral hygiene students enrolled in the diploma and degree programmes. To describe a trend in the throughputs of the diploma and degree programmes.

\section{MATERIALS AND METHODS}

Study design

This was a retrospective, comparative cross-sectional study in which existing academic records were reviewed.

\section{Target population}

The sampling frame consisted of academic records of oral hygiene students who were enrolled in the diploma and degree programmes at Sefako Makgatho Health Sciences University during the period 2011 to 2014 i.e. academic records of three cohorts of first year oral hygiene students enrolled in the diploma and degree programmes for the calendar years 2011 through 2013 and 2012 through 2014 respectively were followed up.

\section{Study sample}

Every available record was studied

\section{Data collection}

Data related to the demographic characteristics of the students, the numbers enrolled, numbers who dropped out, and the numbers who graduated were acquired and then captured in Microsoft Excel software.

Definition of variables and terms

Gender refers to student sex as recorded in the academic records. Population group breakdown of students into Black, Indian, Coloured and White was applied according to the Population Registration Act of 1950. ${ }^{13}$

Progress to qualification refers to enrolment and academic progress. Regulation time is the period of time normally expected for completion of the qualification i.e. two years for a diploma vs three years for a degree.

Throughput is how many students who started studying complete the course of study. This may also be measured by the number of students who do not drop out. ${ }^{14}$ It is also referred to as the completion rate, or graduation rate. ${ }^{3}$ Firsttimer refers to a student who was enrolled in a year of study for the first time.

\section{Ethical considerations}

Ethical approval for the study was granted by the Ethics Committee of Sefako Makgatho Health Sciences University (SMREC/D/198/2019). Permission to conduct the study was granted by the Chief Executive Officer (CEO) of the Oral Health Centre.

\begin{tabular}{|c|c|c|c|c|}
\hline \multirow[t]{2}{*}{ Gender } & \multicolumn{2}{|c|}{ Programmes } & Total $\mathbf{n}(\%)$ & Chi-Square Test \\
\hline & $\begin{array}{l}\text { Diploma } \\
\text { (calendar years } 2011 \text { through } \\
2013) n(\%)\end{array}$ & $\begin{array}{l}\text { Degree } \\
\text { (calendar years } 2012 \text { through } \\
\text { 2014) n (\%) }\end{array}$ & & \\
\hline Male & $15(50)$ & $11(39.3)$ & $26(44.8)$ & \\
\hline Female & $15(50)$ & $17(60.7)$ & $32(55.2)$ & .412 \\
\hline Total & $30(100)$ & $28(100)$ & $58(100)$ & \\
\hline
\end{tabular}

\section{Table 2: Racial composition by programme type}

\section{Race}

\section{Programmes}

Degree

(calendar years 2012 through 2014) n (\%)

\section{Diploma}

(calendar years 2011 through 2013) n (\%)
Total $\mathbf{n}(\%)$

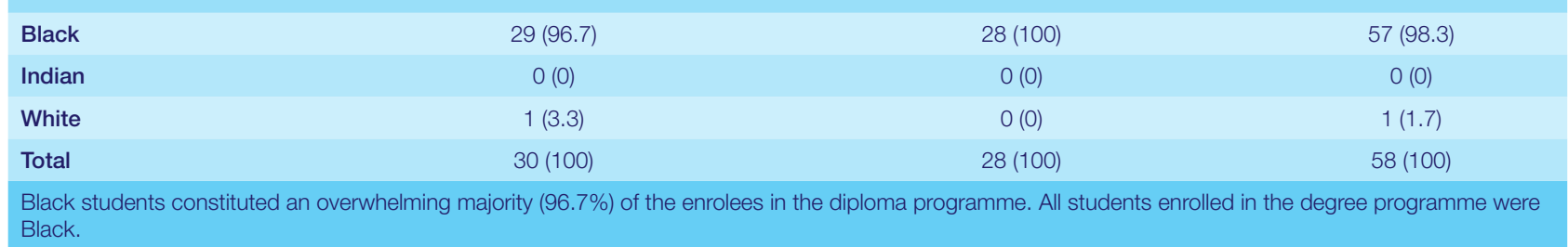




\section{STATISTICAL ANALYSIS/HYPOTHESIS TESTING}

Collected data were subjected to univariate and bivariate analysis in Statistical Package for the Social Sciences (SPSS) software. Frequencies, means and proportions were calculated. Chi-square tests were performed to test the statistical significance of the differences in proportions. Chi-square tests for trend were performed to investigate trends in the throughputs of the diploma and degree programmes. The chosen significance level of the tests was a p-value less than 0.05 .

\section{Results}

Academic records of three cohorts of first year oral hygiene students enrolled in the diploma and degree programmes for the calendar years 2011 through 2013 and 2012 through 2014 respectively were followed up and analysed.

\section{Discussion}

This study set out to determine the contribution of the oral hygiene programs of SMU towards the oral health personnel needs of the country. The progress to qualification of three cohorts of first year oral hygiene students enrolled in the diploma and degree programs was tracked and compared. Trends in the throughputs of the programs were also determined.

\section{Demographic characteristics}

The results of this study indicate that the number of students enrolled in both programmes during calendar years 2011 through 2013 was similar (Table 1). It is difficult to explain this result, but it might be related to the limit in the maximum number of students that can register in the course.

The current study found that female students constituted the majority of enrolees for the degree programme (Table 1). The present findings seem to be consistent with other research which found that female students comprise the majority of students in the oral health sciences. ${ }^{15,16}$

The results of this study show that Black students constituted an overwhelming majority (96.9\%) of the enrolees (Table 2). This finding is in keeping with the legacy of SMU predecessor institutions. Medunsa, the Medical University of Southern Africa, was founded in 1976 to address both the underrepresentation of blacks in the health professions and the lack of good health care in the homelands. The university trained most of the black physicians, dentists, veterinarians, and allied health professionals in South Africa. ${ }^{17}$

The current study found that first-timers constituted $85.7 \%$ and $76.7 \%$ of the enrolees for the degree and diploma

\begin{tabular}{|c|c|c|c|c|}
\hline \multirow[t]{2}{*}{ First-timers } & \multicolumn{2}{|c|}{ Programmes } & Total $\mathbf{n}(\%)$ & Chi-Square Test \\
\hline & $\begin{array}{l}\text { Diploma } \\
\text { (calendar years } 2011 \text { through } \\
\text { 2013) }\end{array}$ & $\begin{array}{l}\text { Degree } \\
\text { (calendar years } 2012 \text { through } \\
\text { 2014) }\end{array}$ & & \\
\hline Yes & $23(76.7)$ & $24(85.7)$ & $47(81)$ & \\
\hline No & 7 (23.3) & $4(14.3)$ & $11(19)$ & .380 \\
\hline Total & $30(100)$ & $28(100)$ & $58(100)$ & \\
\hline
\end{tabular}

Table 4: Pass rates for first year diploma students across levels of cohorts

\begin{tabular}{|c|c|c|c|c|}
\hline \multirow{2}{*}{ Cohorts } & \multicolumn{2}{|c|}{ Examination Results } & \multirow[t]{2}{*}{ Total n (\%) } & \multirow{2}{*}{ Fisher's Exact Test } \\
\hline & Pass & Fail & & \\
\hline 2011 & $12(85.7)$ & $2(14.3)$ & $14(100)^{\star}$ & \multirow{4}{*}{.000} \\
\hline 2012 & $9(75)$ & $3(25)$ & $12(100)$ & \\
\hline 2013 & $2(66.7)$ & $1(33.3)$ & $3(100)$ & \\
\hline Total & $23(79.3)$ & $6(20.7)$ & $29(100)^{\star}$ & \\
\hline \multicolumn{5}{|c|}{ *Number of students that interrupted studies } \\
\hline
\end{tabular}

Table 5: Pass rates for second year diploma students across levels of cohorts

\begin{tabular}{lcccc} 
& \multicolumn{2}{c}{ Examination Results } & Total $\mathbf{n}(\%)$ & Fisher's Exact Test \\
\hline 2011 & Pass & Fail & $11(100)^{*}$ & .000 \\
2012 & $9(81.8)$ & $2(18.2)$ & $8(100)^{*}$ & $2(100)$ \\
2013 & $5(62.5)$ & $3(37.5)$ & $21(100)^{* *}$ & \\
\hline Total & $2(100)$ & $0(0)$ &
\end{tabular}

*Number of students that dropped out

The average pass rate among cohorts of second year diploma students was $81.4 \%$ with a range of $62.5 \%$ to $100 \%$. There was substantial evidence ( $\mathrm{p}$ $=0.000)$ to reject the null hypothesis that the pass rate was constant across levels of cohorts. Two out of thirty (6.7\%) students who started the course dropped out. 


\begin{tabular}{|c|c|c|c|c|}
\hline \multirow{2}{*}{ Cohorts } & \multicolumn{2}{|c|}{ Examination Results } & \multirow[t]{2}{*}{ Total n (\%) } & \multirow{2}{*}{ Fisher's Exact Test } \\
\hline & Pass & Fail & & \\
\hline 2012 & $4(80)$ & $1(20)$ & $5(100)$ & \multirow{4}{*}{.000} \\
\hline 2013 & 5 (83.3) & $1(16.7)$ & $6(100)^{\star \star}$ & \\
\hline 2014 & $9(100)$ & $0(0)$ & $9(100)^{\star \star}$ & \\
\hline Total & $18(90)$ & $2(10)$ & $20(100)^{\star \star \star \star}$ & \\
\hline
\end{tabular}

Number of students that dropped out

The average pass rate among cohorts of second year degree students was 87.8 with a range of $80 \%$ to $100 \%$. There was substantial evidence ( $p=0.000)$ to reject the null hypothesis that the pass rate was constant across levels of cohorts. Four out of twenty-eight (14.3\%) students who started the course dropped out.

\begin{tabular}{|c|c|c|c|c|}
\hline \multirow{2}{*}{ Cohorts } & \multicolumn{2}{|c|}{ Examination Results } & \multirow[t]{2}{*}{ Total n (\%) } & \multirow{2}{*}{ Fisher's Exact Test } \\
\hline & Pass & Fail & & \\
\hline 2012 & $4(100)$ & $0(0)$ & $4(100)$ & \multirow{4}{*}{.000} \\
\hline 2013 & $5(100)$ & $0(0)$ & $5(100)$ & \\
\hline 2014 & $9(100)$ & $0(0)$ & $9(100)$ & \\
\hline Total & $18(100)$ & $0(0)$ & $18(100)$ & \\
\hline
\end{tabular}

The average pass rate among cohorts of third year degree students was $100 \%$. There was substantial evidence $(p=0.000)$ to reject the null hypothesis that the pass rate was constant across levels of cohorts

\begin{tabular}{|c|c|c|c|c|}
\hline \multirow[b]{2}{*}{$\begin{array}{l}\text { Completed the course in } \\
\text { regulation time }\end{array}$} & \multicolumn{3}{|c|}{ Cohorts } & \multirow[b]{2}{*}{ Chi-Square test for trend } \\
\hline & $\begin{array}{l}2011 \\
\text { n (\%) }\end{array}$ & $\begin{array}{l}2012 \\
\text { n (\%) }\end{array}$ & $\begin{array}{l}2013 \\
\text { n (\%) }\end{array}$ & \\
\hline Yes & $9(60)$ & $5(41.7)$ & $2(66.7)$ & \multirow{3}{*}{.741} \\
\hline No & $6(40)$ & 7 (58.3) & 1 (33.3) & \\
\hline Total & $15(100)$ & $12(100)$ & $3(100)$ & \\
\hline
\end{tabular}

programmes respectively, while repeaters, conversely, constituted an average of slightly less than $20 \%(18.8 \%)$ of first year enrolees in either programme (Table 3). This figure is broadly consistent with an earlier range of values, $8.1 \%$ to $26.9 \%$, discovered for the dental programme at the same institution. ${ }^{4}$ The welcome reduction in the proportion of first year repeaters between the diploma and degree programmes is encouraging.

\section{Progress tracking}

The results of this investigation showed that the average first year pass rate (83.8\% vs $75.8 \%$ ) for the degree programme was $8 \%$ higher than that for the diploma programme (Tables 4 and 6). This finding has not previously been described. It is difficult to explain this result, but it might be related to the student selection process.

It is encouraging to compare the first year pass rate of the oral hygiene course with that of the of dental therapy and dental courses at the same institution. It is noteworthy that the pass rate for the oral hygiene degree programme was similar $(83.8 \%$ vs $83.6 \%)$ to that of the first year dental therapy programme. ${ }^{5}$ However, they were both slightly lower than that of the corresponding dental programme (87\%). ${ }^{4}$

The current study found that the range of the pass rate for the degree programme was $18.5 \%$ larger than that of the diploma programme (37.5\% vs $19 \%$, Tables 4 and 6$)$. This finding indicates that the pass rate for the degree programme was highly variable (Table 6). The most interesting finding was that the first year pass rate increased as the cohort size increased (Table 6). These results do not support previous research which found an inverse relationship between class size and academic achievement for small class sizes. ${ }^{18,19}$ The class size for the degree programme has steadily increased from a low of 8 in 2012 to a high of 25 in 2021. Further research should be done to investigate the effect of class size on pass rate.

The current study found an improvement in the pass rates from one year of study to the next (Table 4-8) These welcome findings suggest that the academic and mentoring support offered in both programmes was effective.

The results of this study showed that the dropout rate for the degree programme was more than twice (14.3\% vs $6.7 \%$ ) as high as that for the diploma programme. The findings of the current study differ sharply from some published studies - the dropout rate is much lower than previously reported. The Council for Higher Education ( $\mathrm{CHE}$ ) found that the dropout rate ranged between 35\% and $41 \% .20$ The Stellenbosch University working paper reported a dropout rate of $28.4 \% .{ }^{21}$

It may well be that factors such as race, gender, matriculation score and poverty, which are widely accepted to be strongly associated with dropout in South Africa played a little role in this study. ${ }^{22-24}$ The relative ease of transferring from one undergraduate degree programme to another compared with transferring from a diploma 


\begin{tabular}{|c|c|c|c|c|}
\hline \multirow[b]{2}{*}{$\begin{array}{l}\text { Completed the course in } \\
\text { regulation time }\end{array}$} & \multicolumn{3}{|c|}{ Cohorts } & \multirow[b]{2}{*}{ Chi-Square test for trend } \\
\hline & $\begin{array}{l}2011 \\
\text { n (\%) }\end{array}$ & $\begin{array}{l}2012 \\
n(\%)\end{array}$ & $\begin{array}{l}2013 \\
n(\%)\end{array}$ & \\
\hline Yes & $4(50)$ & $5(55.6)$ & $9(81.8)$ & \multirow{3}{*}{.138} \\
\hline No & $4(50)$ & $4(44.4)$ & 2 (18.2) & \\
\hline Total & $8(100)$ & $9(100)$ & $11(100)$ & \\
\hline \multicolumn{5}{|c|}{$\begin{array}{l}\text { The average throughput of the degree programme was } 62.5 \% \text { with a range of } 50 \% \text { to } 81.8 \% \text {. The throughput increased as the cohort size increased. How- } \\
\text { ever, there was insufficient evidence }(p=0.138) \text { to reject the null hypothesis of no linear trend between cohort size and completing the course in regulation } \\
\text { time. A combined total of } 18 \text { students from the three cohorts completed the degree and graduated within the regulation time }\end{array}$} \\
\hline
\end{tabular}

Table 11: Combined throughputs by programme type

\begin{tabular}{lccc}
\multicolumn{1}{c}{ Programme type } & \multicolumn{1}{c}{ Completed the course in regulation time } & Total $\mathbf{n}(\%)$ & Chi-Square test \\
\hline Diploma & \multicolumn{1}{c}{ Yes } & No & $30(100)$ \\
Degree & $16(53.3)$ & $14(46.7)$ & $28(100)$ \\
Total & $18(64.3)$ & $10(35.7)$ & $58(100)$ \\
Total & $34(58.6)$ & $24(41.4)$ & $18(100)$ \\
$\begin{array}{l}\text { A combined total of } 16 \text { and } 18 \text { students from the three cohorts completed the diploma and degree programmes respectively and graduated within the reg- } \\
\text { ulation time. There was insufficient evidence }(p=0.397) \text { to reject the null hypothesis that the proportions of combined students who completed the diploma } \\
\text { and degree programmes in regulation time were equal in the population }\end{array}$
\end{tabular}

programme to a degree programme might be a possible explanation for the discrepancy in dropout rates between the programmes. Further work is required to establish the reasons for dropping out.

\section{Throughputs and trends}

The results of this study show that the average throughput of the degree programme was $6.4 \%$ higher than that for the diploma programme (62.5\% vs $56.1 \%)$. Furthermore, the range of throughputs for the degree programme was $25.1 \%$ larger than that for the diploma programme, indicating high variability. Local studies of comparable cohorts were not found - the throughput of oral hygiene courses in the five dental schools in South Africa has not previously been described.

It is encouraging to compare the throughput of the oral hygiene course with that of dental therapy and dental courses at the same institution. It compares favourably with the average throughput of the dental therapy courses and dentistry course, which has been established to be 45 percent and $40 \%$ respectively. ${ }^{4,5}$ It seems possible that these results are due to small class sizes of the oral hygiene programme compared with the other groups of oral health science students. There are, however, other possible explanations.

The findings of the current study differ greatly from the Ministry of Education's target of $25 \%$ graduation rate for a 3-year undergraduate degree. ${ }^{25}$ However, they are broadly consistent with other research. The Council for Higher Education $(\mathrm{CHE})$ found that the throughput rates for 3-year degrees with first year of enrolment in 2010 ranged between $30 \%$ and $59 \% .{ }^{20}$

The results of this study did not show a linear trend between cohort size and completing the course in regulation time for either programme (Tables 8 and 9). This rather disappointing finding means that the increased throughput associated with increased cohort size for the degree programme was not found to be statistically significant. The small cohort sizes found in this study may have affected the power of the Chi square test to detect a trend. It is generally accepted that the power of a test increases with increasing sample size. ${ }^{26}$ Further studies with larger ordered categories of cohorts should be considered to test the null hypothesis.

The results of this study did not show any significant difference in combined output between the diploma and degree programmes (Table 11). This result has not previously been described. It was unexpected in view of the of the difference in the duration of the programmes. The relatively high average throughput of the degree programme is however encouraging (Table 10).

Limitations of the study

Data on age of the students was not available.

\section{CONCLUSION}

The average throughput of the degree programme was higher than that for the diploma programme. The difference was however not statistically significant.

\section{References}

1. South Africa. Government Gazette. Dept. of Health Regulations defining the scope of the profession of oral hygiene. October 2013. Vol 580. No 36944. Available https://www.gov.za/sites/default/files/gcis do cument/201409/36944rg10038gon800.pdf [Accessed 24/03/2021]

2. HPCSA. Statistics. Retrieved from www.hpcsa.co.za/ Publications/Statistics [Accessed 24/03/2021]

3. Jeynes K. In: FACTSHEET: How many South African students graduate? December 2016. Available https:// africacheck.org/factsheets/factsheet-many-southafrican-students-graduate/ [Accessed 24/03/2021].

4. Mthethwa SR, Nyalunga PM, Gugushe TS. Throughputs of two cohorts of dental students at Sefako Makgatho 
Health Sciences University: A comparison. SADJ 2020; 75(6):235-41

5. Masetla MM, Mthethwa SR. Dental Therapy Student cohorts: Trends in enrolment and progress at a South African University. SADJ 2018; 73(6): 406-10

6. World Health Organization. Dentistry personnel density (per 1000 population) Retrieved from http://data. un.org/Data.aspx? $\mathrm{q}=$ dentistry $\& \mathrm{~d}=\mathrm{WHO} \& \mathrm{f}=\mathrm{MEASUR}$ CODE\%3AHRH_28 [Accessed 24/03/2021]

7. HPCSA. Professional Boards. Retrieved from http://www.hpcsa.co.za/PBDentalTherapy[Accessed 24/03/2021]

8. Schutee E. Oral Hygienist- Post Matric. Available: http://www.postmatric.co.za/oral-hygienist/ Accessed [24/03/2021]

9. Australian Dental Association. Dental Hygienist. Retrieved from http://www.ada.org.au/ dentalprofessionals/hygienist.aspx [Accessed 05/12/2018]

10. American Dental Association. Dental Hygienist. Retrieved from https://www.ada.org/en/educationcareers/careers-in-dentistry/dental-team-careers/ dental-hygienist [Accessed 05/12/2018]

11. Bhayat A, Chikte U. Human Resources for Oral Health Care in South Africa: A 2018 Update. Int J Environ Res. Public Health 2019; 16: 1668; doi:10.3390/ ijerph16101668

12. Department of Health. HRH Strategy for the Health Sector: 2012/13 - 2016/17 Retrieved http://www. hst.org.za/publications/NonHST\%20Publications/ hrh_strategy-2.pdf [Accessed 24/03/2021]

13. Union of South Africa (1950). Population Registration Act, No. 30 of 1950, in SA Government Gazette.

14. van Broekhuizen H. In: FACTSHEET: How many South African students graduate? December 2016. Available https://africacheck.org/factsheets/ factsheet-many-south-african-students-graduate/ [Accessed 01 November 2017]

15. Lalloo R, Ayo-Yusuf OA, Yengopal V. Early-phase dental students' motivations and expectations concerning the study and profession of dentistry. SADJ. 2008; 63(4): 216-20.

16. Singh PK, Combrink M. Profile of the dental therapy graduate at the University of KwaZulu-Natal. South African Dental Journal 2011; 66(10): 468,470-4

17. Haynes MA, Lee AB. Medunsa and the training of black doctors for South Africa. Acad Med. 1995 Feb;70(2):115-21.

18. Bandiera, O., V. Larcinese and I. Rasul. 2010. Heterogeneous class size effect: New evidence from a panel of university students. Economic Journal 120 (549): 1149-1459.

19. Rachmander M, Naude MJ. The relationship between increasing enrolment and student academic achievement in higher education, Africa Education Review 2018;15(4):135-51

20. Council on Higher Education. Vital Stats Public Higher Education 2015. Pretoria: CHE; 2017. Retrieved from: https://www.usaf.ac.za/wp-content/ uploads/2017/10/CHE_VitalStats_Public-HigherEducation-2015.pdf [Accessed 03/09/2021]

21. Van Broekhuizen $H$, van der Berg $S$, Hofmeyr $H$. Higher Education Access and Outcomes for the 2008 National Matric Cohort. Stellenbosch Economic
Working Papers: 16/16; 2016 Retrieved from: https:// resep.sun.ac.za/wp-content/uploads/2016/10/VanBroekhuizen-et-al.pdf [Accessed 24/03/2021]

22. Council on Higher Education (CHE). A proposal for undergraduate curriculum reform in South Africa: The case for a flexible curriculum structure. Pretoria: $\mathrm{CHE}$; 2013

23. Letseka M, Maile S. High university dropout rates: A threat to South Africa's future. Pretoria: Human Science Research Council; 2008.

24. Fiske EB and Ladd HF. Elusive equity: Education reform in post-apartheid South Africa. Washington, D.C: Brookings Institution Press, 2004.

25. Ministry of Education. National Plan for Higher Education in South Africa. Retrieved from http:/www. justice.gov.za/commissions/FeesHET/docs/2001NationalPlanForHigher Education.pdf [Accessed 03/09/2021].

26. Petrie A, Sabin C. Medical Statistics at a Glance, 2nd ed. Massachusetts: Blackwell Publishing, 2005: 44. 